\title{
Music meets robotics: a prospective randomized study on motivation during robot aided therapy
}

\author{
Kilian Baur $^{1,2^{*}+}$ (D), Florina Speth ${ }^{1,2,3+}$, Aniket Nagle ${ }^{1,2}$, Robert Riener ${ }^{1,2}$ and Verena Klamroth-Marganska $a^{1,2,4}$
}

\begin{abstract}
Background: Robots have been successfully applied in motor training during neurorehabilitation. As music is known to improve motor function and motivation in neurorehabilitation training, we aimed at integrating music creation into robotic-assisted motor therapy. We developed a virtual game-like environment with music for the arm therapy robot ARMin, containing four different motion training conditions: a condition promoting creativity $(\mathrm{C}+)$ and one not promoting creativity $\left(\mathrm{C}_{-}\right)$, each in a condition with $(\mathrm{V}+)$ and without $(\mathrm{V}-$ ) a visual display (i.e., a monitor). The visual display was presenting the game workspace but not contributing to the creative process itself. In all four conditions the therapy robot haptically displayed the game workspace. Our aim was to asses the effects of creativity and visual display on motivation.
\end{abstract}

Methods: In a prospective randomized single-center study, healthy participants were randomly assigned to play two of the four training conditions, either with $(\mathrm{V}+)$ or without visual display $(\mathrm{V}-)$. In the third round, the participants played a repetition of the preferred condition of the two first rounds, this time with a new $V$ condition (i.e., with or without visual display). For each of the three rounds, motivation was measured with the Intrinsic Motivation Inventory (IMI) in the subscales interest/enjoyment, perceived choice, value/usefulness, and man-machine-relation. We recorded the actual training time, the time of free movement, and the velocity profile and administered a questionnaire to measure perceived training time and perceived effort. All measures were analysed using linear mixed models. Furthermore, we asked if the participants would like to receive the created music piece.

Results: Sixteen healthy subjects (ten males, six females, mean age: 27.2 years, standard deviation: 4.1 years) with no known motor or cognitive deficit participated. Promotion of creativity (i.e., $C+$ instead of $C-$ ) significantly increased the IMI-item interest/enjoyment $(p=0.001)$ and the IMI-item perceived choice $(p=0.010)$. We found no significant effects in the IMI-items man-machine relation and value/usefulness. Conditions promoting creativity (with or without visual display) were preferred compared to the ones not promoting creativity. An interaction effect of promotion of creativity and omission of visual display was present for training time $(p=0.013)$ and training intensity $(p<0.001)$. No differences in relative perceived training time, perceived effort, and perceived value among the four training conditions were found.

(Continued on next page)

*Correspondence: kilian.baur@hest.ethz.ch

${ }^{+}$Kilian Baur and Florina Speth contributed equally to this work.

1 Sensory-Motor Systems Lab, Department of Health Sciences and Technology,

Swiss Federal Institute of Technology (ETH Zurich), Tannenstrasse 1, 8092

Zurich, Switzerland

${ }^{2}$ Spinal Cord Injury Center, University Hospital Balgrist, University of Zurich,

Forchstrasse 340, 8008 Zurich, Switzerland

Full list of author information is available at the end of the article

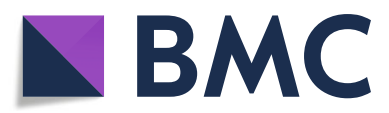

(c) The Author(s). 2018 Open Access This article is distributed under the terms of the Creative Commons Attribution 4.0 International License (http://creativecommons.org/licenses/by/4.0/), which permits unrestricted use, distribution, and reproduction in any medium, provided you give appropriate credit to the original author(s) and the source, provide a link to the Creative Commons license, and indicate if changes were made. The Creative Commons Public Domain Dedication waiver (http://creativecommons.org/publicdomain/zero/1.0/) applies to the data made available in this article, unless otherwise stated. 
(Continued from previous page)

Conclusions: Promoting creativity in a visuo-audio-haptic or audio-haptic environment increases motivation in robot-assisted therapy. We demonstrated the feasibility of performing an audio-haptic music creation task and recommend to try the system on patients with neuromuscular disorders.

Trial registration: ClinicalTrials.gov, NCT02720341. Registered 25 March 2016, https:/clinicaltrials.gov/ct2/show/ NCT02720341

Keywords: Robotic arm rehabilitation, Creativity, Intrinsic motivation, Audio-haptic display, Music therapy, Serious games, Stroke, User interface

\section{Background}

Following a stroke, $80-90 \%$ of patients suffer from arm paresis, which remains chronic in about $30-40 \%$ of all cases [1-3]. Task-oriented, intensive, and motivational training is important to increase arm function post-stroke $[2,4-8]$.

Intensity is recognized as a key feature of successful rehabilitation therapy [9]. Robots in neurorehabilitation allow for highly-intensive, task-oriented training and have the potential to be superior to conventional therapies (i.e., physical or occupational therapy) in improving motor function post-stroke [10]. Robotic therapy may embed functional training tasks into computer games to facilitate motor learning and to stimulate motivation [11].

Autonomy, competence, and relatedness can be regarded as the main components of intrinsic motivation $[12,13]$. While extrinsic motivation can be described as a goal-directed drive towards an externally provided reward (e.g., a score in a game), intrinsic motivation is a process oriented and internally provided reward due to a satisfying, interesting, meaningful or enjoyable activity $[14,15]$. The knowledge regarding the meaningfulness of an activity is a positive determinant of patient motivation [7]. Thus, for patients, an activity should not only be enjoyable, but also lead to a rehabilitation progress. Furthermore, patient engagement is related to the expected reduction of impairment during game-based therapy in stroke [16].

Activities with a close relation to intrinsic motivation are frequently associated with activities promoting creativity [17-19]. This might be because activities promoting creativity involve one's own accord, active decision making, and a resulting product, thus satisfying the need of autonomy, competence, and relatedness [12, 20-22].

In addition to encouraging creativity, music is a promising stimulator for intrinsic motivation in the context of rehabilitation [23, 24]. Music effectively promotes poststroke recovery in motor and cognitive functions, and furthermore in emotional and social domains [25-31]. Studies that compared conventional therapy forms to therapy tasks embedded in active music making revealed that music-associated training increases the level of motivation significantly [24, 32].

Auditory displays have already been determined to be effective for navigation within complex systems [33]. Accordingly, sound is an audible source for navigation through the execution of a task in virtual scenarios without the need for a visual display unit, the advantage being that the visual focus can be on the trained limb rather than a graphical display, thus promoting visuo-motor control [34, 35].

We developed tasks for robot-assisted training of the arm that aim to increase intrinsic motivation with a focussed stimulation of the two aspects: creativity and music. To investigate whether a music condition promoting creativity influences motivation differently than a music condition not promoting creativity, we compared motivational effects of both versions. We investigated the effect of the presence or absence of a visual display for both conditions regarding promotion of creativity. As the training goal of the presented gamified task is to induce high intensity during exercise, the game is operated by repetitive horizontal movements.

For this current study, we designed audio-haptic tasks in a way that they can be performed either with visual display (i.e., a monitor presenting the game workspace) as an audio-visuo-haptic environment or without a visual display as an audio-haptic environment only. To reduce the cognitive load of the participants and have more cognitive resources for creation and decision making processes, we designed the visual display and the haptic environment such that they both presented the same game workspace [36]. Accordingly, the visuals were not essential to complete the audio-haptic task.

Given these related works, the primary hypothesis was that a gamified task promoting creativity embedded in a task for motor therapy increases intrinsic motivation more than a gamified task not promoting creativity. Our second hypothesis was that a gamified task in motor therapy without visual display increases intrinsic motivation more than a gamified task with visual display. Moreover, 
we hypothesized that promoting creativity and omitting a visual display would increase total training time, free movement time and perceived product value. We further hypothesized that promoting creativity and omitting a visual display would reduce energy expenditure, relative perceived training time and perceived effort.

\section{Methods}

We conducted a prospective randomized single-center study in Zurich, Switzerland. Approval was obtained from the responsible Ethical Committee (KEK-ZH-Nr. 20150013, Zurich, Switzerland). The study is registered at ClinicalTrials.gov (identifier: NCT02720341).

\section{Subjects}

Sixteen healthy subjects with no known motor or cognitive deficit were to be recruited among the population of Zurich. Most of them were employees and students of ETH Zurich.

\section{Technical setup}

The study was performed with the ARMin arm rehabilitation robot generation IV shown in Fig. 1. ARMin is a seven-degree-of-freedom exoskeleton robot for arm therapy of patients with neurological disease. It was developed by the groups of Riener at ETH Zurich and Dietz/Curt

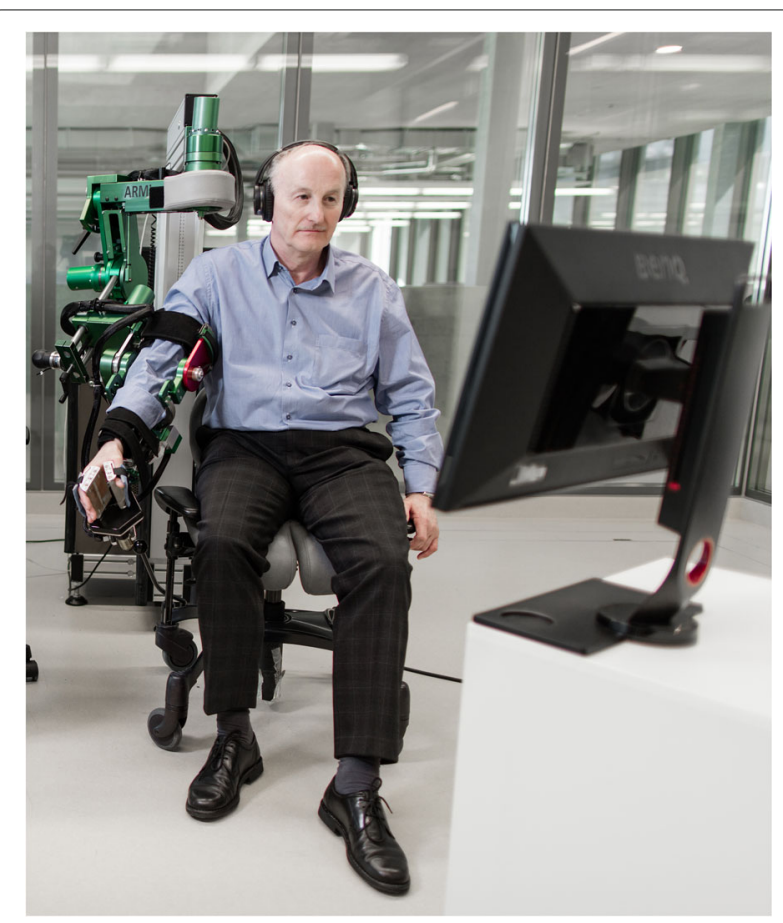

Fig. 1 ARMin arm rehabilitation robot. Additionally for this study, a keyboard was placed close to the participant's left hand so that the space bar could be used as input device at the University of Zürich [37, 38] (technical details: see Appendix ARMin).

\section{Game environment}

The game environment was developed targeting horizontal movements at table height as this type of arm motion is required for activities of daily living, such as cleaning a table or moving objects on a table. Such training activities are already provided in several upper limb training devices for stroke therapy [38, 39].

Four conditions were developed in the Unity game engine [40]: A music task promoting creativity played without a visual display $(\mathrm{C}+\mathrm{V}-)$, a music task promoting creativity played with a visual display $(\mathrm{C}+\mathrm{V}+)$, a music task not promoting creativity played without a visual display $(\mathrm{C}-\mathrm{V}-)$ and a music task not promoting creativity played with a visual display $(\mathrm{C}-\mathrm{V}+)$. All four conditions used the same audio-haptic environment. In this environment, participants have to select one out of two sound samples positioned to the left and to the right, respectively, several times per condition. In the conditions with visual displays, the environment was complemented with visual feedback (audio-visuo-haptic environment).

To provide task oriented training we haptically simulated an environment of moving objects on a table. Subjects could only move the end effector of the robot horizontally. Downward movements were restricted by a virtual table that was set at the level of the shoulder and provided arm support. The horizontal left-right movement served as game input. Therefore, the game can be considered as a one-degree-of-freedom task. As illustrated in Fig. 2, the haptic display included haptic walls at the end of the workspace (HWs). Sound zones (SZ) and center zones (CZ) were action zones where a vibrotactile haptic feedback (i.e., band-limited white noise) was provided at the hand module of the robot. The vibrotactile haptic feedback was induced via DC motors at the wrist joint of the robot. As a perceivable state indicator (i.e., being inside or outside of a SZ) for the participants, the vibrotactile haptic feedback was not breaking or stopping the participant's movement. None of the participants commented on the vibrotactile feedback.

While in $\mathrm{C}-\mathrm{V}+$ and $\mathrm{C}+\mathrm{V}+$, the task was visualized on a monitor, in $\mathrm{C}-\mathrm{V}-$ and $\mathrm{C}+\mathrm{V}-$, the same movements were performed without visual feedback (i.e., without a monitor).

The sounds used in the SZs consisted of fourteen different pairs of sound samples and two pairs of sound effects. These sixteen pairs of music creation elements were presented to the participant in fixed order. The sound samples consisted of synthetic piano, mallets, marimba, vibraphone, pads, drums, hi-hats, and claps. Harmonic 


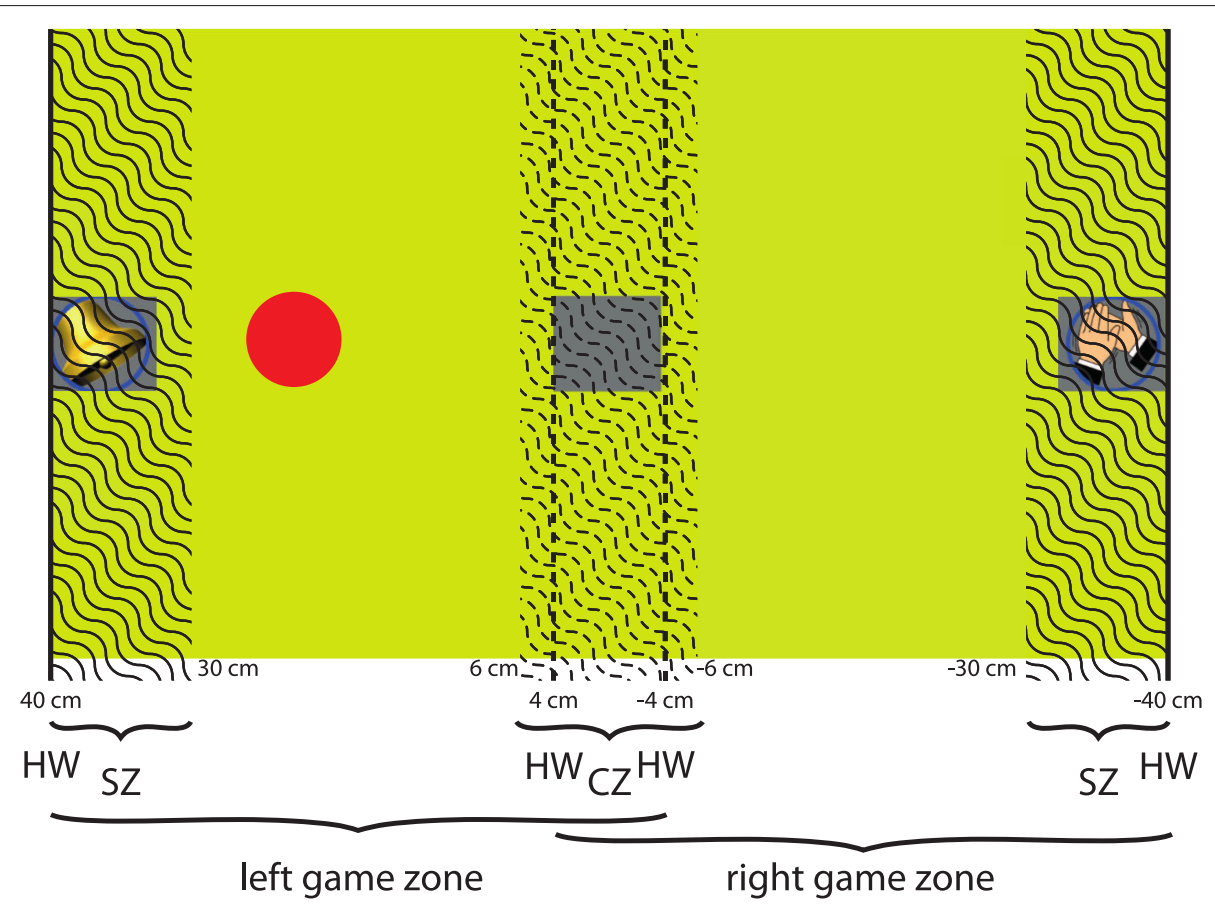

Fig. 2 Screenshot of the tasks in V+ conditions with additional map of haptic elements: The visual environment displays sound icons (e.g., a bell or hands clapping) within sound zones (SZ), and a grey square that marks the center zone (CZ). SZs and CZ (wave-marked areas) are active zones where a vibrotactile haptic feedback is provided. The scene is limited by two haptic walls (HW, solid lines). HWs (dotted lines) limiting CZ are only turned on in the game phases where only the left or the right game zone is used. The red circle is the game "cursor". All units are in centimeters

elements were tuned in C-Major. Each sound sample lasted six seconds and was played in a loop with a tempo of 80 beats per minute. The two pairs of sound effects (i.e., modulators) were Reverb and Echo, and Resonance and Arpeggiator. To ensure a well-formed, aesthetic and pleasant music structure, the sound samples and the modulators were designed such that they suit to each other when playing simultaneously (see Appendix Sound examples). The underlying music composition was developed with the commercial music software Abelton Live 8 (Abelton). Subjects listened to the sounds using Sony MDR-7506® headphones.

All conditions used the same audio-haptic environment wherein the haptic walls together with instrument sounds gave feedback about the position in the game.

\section{Game rules}

The game rules for all four conditions are illustrated in Fig. 3. Each of the four conditions consisted of of three game phases in fixed order, namely an active movement phase, a listening phase, and a final phase). The three game phases were different in the conditions promoting creativity $(\mathrm{C}+)$ and in the conditions not promoting creativity $(\mathrm{C}-)$ but independent of the inclusion or omission of a visual display.
The only difference between the $\mathrm{V}+$ and the $\mathrm{V}$ - conditions was the workspace visualization on a monitor which was either provided $\left(\mathrm{V}^{+}\right)$or omitted $(\mathrm{V}-)$.

\section{Detailed game rules for the $C+$ condition}

In the active movement phase of $\mathrm{C}+$ conditions, two sounds were presented, one in the right and one in the left SZ. By moving the arm (fixed in ARMin) into the SZs, the subject could listen to the corresponding sound. Pressing the spacebar key while being in the SZ activated that sound. Activating a sound caused that sound sample to play in a loop. Once a sound was activated, subjects had to move between CZ and SZ. The more they moved, the more the volume increased. The range of volume was from no sound to comfortable volume, as assessed during study instruction. When they stopped moving, the sound was played in a loop with low volume. After at least three repetitions, the subject could start the next round by pressing the space key.

In the listening phase, the resulting music composition was played back to the subjects at a constant volume. Subjects were invited to listen only or to move to the music freely.

In the final phase, the last four activated sounds of the piece were played back. To keep the volume up, movement 


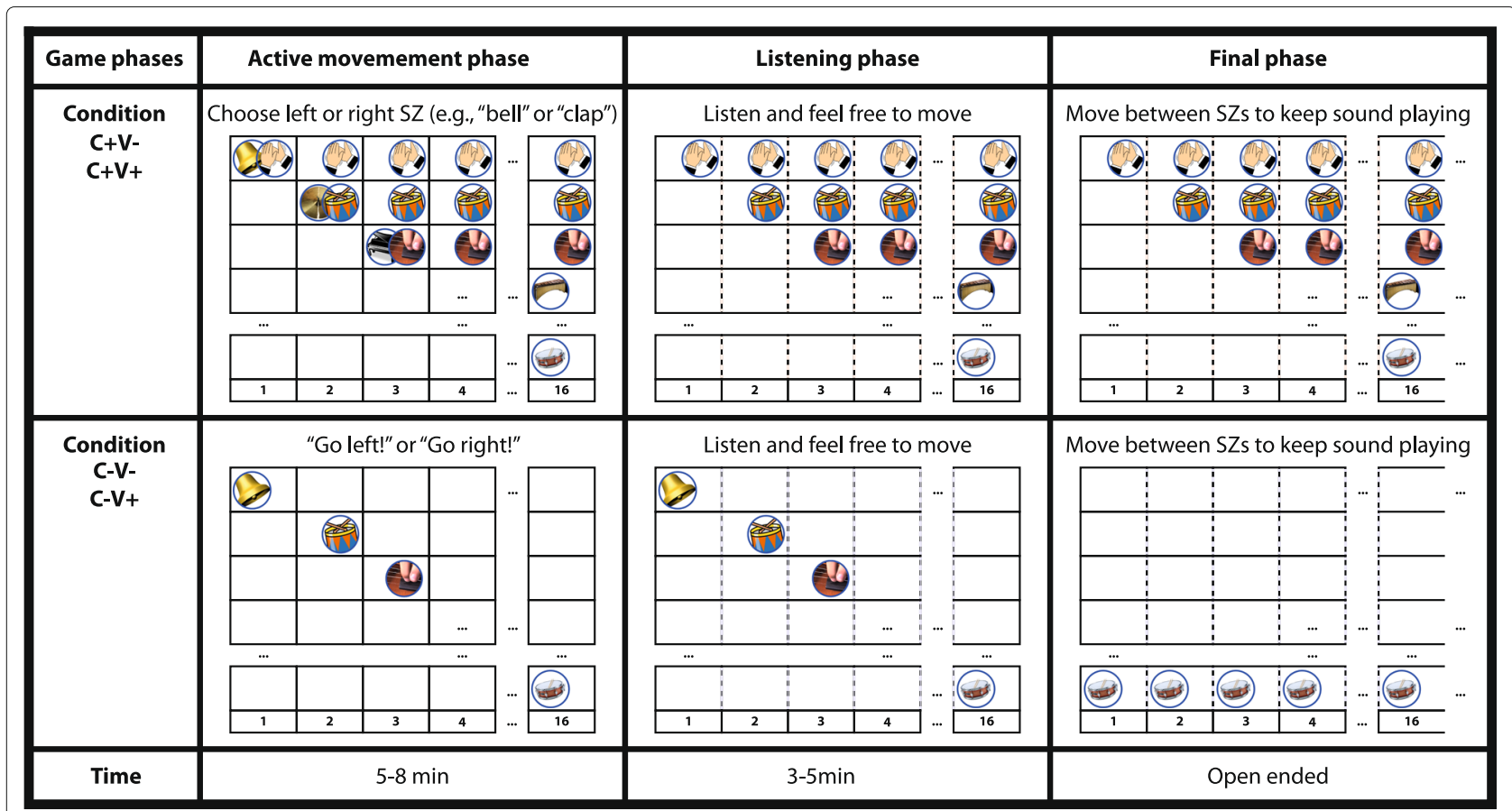

Fig. 3 Game rules for all four conditions. C+ conditions and C- conditions for all three game phases (i.e., active movement phase, listening phase, final phase) are presented. In C+ conditions, four successively activated sounds add up to a music piece (upper field, from top to bottom: claps, drums, guitars, marimba, ...). In C- conditions (lower field), each consecutively activated sound is played alone

between the two SZs was needed. As soon as no movement reaching out to the SZs was performed, the volume decreased. The final phase ended whenever the user wanted.

\section{Detailed game rules for the $\mathrm{C}$ - condition}

In the active movement phase of the $\mathrm{C}$ - conditions, subjects could not choose sounds. They followed verbal instructions, either "go left" or "go right". Upon moving to the correct SZ, the related sound was played. After five movements between $\mathrm{SZ}$ and $\mathrm{CZ}$, the next instruction was given. Two additional movements had to be made in the $\mathrm{C}$ - condition compared to the three movements in the $\mathrm{C}+$ condition to balance out the expected exploring behavior of the participants in the C+ condition. This exploring behavior was assumed to be at least one movement towards each side. The direction was randomly generated for each round. This was performed over fourteen sounds and two sound effects. Although participants never tried to cheat, i.e., go into the opposite direction than instructed, would not have been possible. The next round of sounds are not played unless instructions are followed.

In the listening phase, the resulting music composition was played back to the subjects at a constant volume. Subjects were invited to listen only or to move to the music freely.
In the final phase, the presented sound consisted of the last four sounds activated in the active movement phase. These sounds were displayed serially and in a loop. To keep the volume up, subjects had to continue the movements between the two SZs. As soon as no movement was performed, the volume decreased. The final phase ended whenever the user wanted.

\section{Study procedure}

Considering the exploratory type of the study and to counterbalance the groups, we decided that $n=16$ was a possible subject count [41]. Accordingly, we created sixteen cards with the four groups A, B, C, D printed on it. Table 1 shows the four groups and their corresponding conditions. Each new subject was asked to draw from this deck of cards. Subjects were assigned the group and an increasing ID within the group, according to the card they drew. A card once drawn was discarded. In the end we achieved random assignment for the sixteen subjects among the four groups.

The subject was seated in ARMin with their right arm fixed to the device. An audio guide explained the game rules with the example of $\mathrm{C}+\mathrm{V}+$. It explained how to position and move the arm to first explore and then activate sound samples and sound effects. Two repetitions of $\mathrm{C}+\mathrm{V}+$ were explained through verbally instructed game 
Table 1 Groups A, B, C, D (4 subjects each): order of conditions for rounds $1-3 ; \mathrm{C}+=$ promoting creativity; $\mathrm{C}-=$ not promoting creativity; $V_{+}=$with visual display; $V_{-}=$without visual display

\begin{tabular}{llll}
\hline Round & 1 & 2 & 3 \\
\hline Group A & $\mathrm{C}+\mathrm{V}_{+}$ & $\mathrm{C}-\mathrm{V}_{+}$ & Preferred task without \\
Group B & $\mathrm{C}-\mathrm{V}_{+}$ & $\mathrm{C}+\mathrm{V}_{+}$ & visual display $\left(\mathrm{C}+\mathrm{V}-\right.$ or $\left.\mathrm{C}-\mathrm{V}_{-}\right)$ \\
Group C & $\mathrm{C}+\mathrm{V}_{-}$ & $\mathrm{C}-\mathrm{V}_{-}$ & Preferred task with visual \\
Group D & $\mathrm{C}-\mathrm{V}_{-}$ & $\mathrm{C}+\mathrm{V}_{-}$ & display $(\mathrm{C}+\mathrm{V}+$ or $\mathrm{C}-\mathrm{V}+)$ \\
\hline
\end{tabular}

playing by the audio guide which was triggered by game states. The audio guide explained also, that in the listening phase the composed music was replayed, and that in the final phase a movement stop would decrease the sound volume until the participant wanted to stop the round by telling the experimenter. Finally, the differences to other conditions, i.e., being instructed where to move $(\mathrm{C}-)$ and playing without a visual display $(\mathrm{V}-)$, were explained by the audio guide.

After each round, the subject filled in the questionnaires. After the second round, the subject selected a preferred condition. According to that selection, the third round was performed in the preferred creativity condition, i.e., $\mathrm{C}+$ or $\mathrm{C}-$, with the not played visual display condition, i.e., $\mathrm{V}+$ or $\mathrm{V}-$. In order to be able to use the same study protocol for patients at a later time, we aimed to minimize the study time and implicitly the strain for the individual participant. Thus, each subject performed only three of the four possible conditions.

Comments stated by the participants during or after each round were transcribed by the examiner.

\section{Outcome measures}

\section{Primary outcomes}

The Intrinsic Motivation Inventory (IMI) is a multidimensional measurement device for assessment of participants' subjective experience related to a specific activity. While there are many versions of the IMI, in this study, statements of the subscales interest/enjoyment (seven statements), perceived choice (seven statements), value/ usefulness (two statements), man-machine-relation (five statements, in IMI original name of item: relatedness) were used [42]. The statement sentences for each subitem were presented and subjects answered on a Likert scale ranging from 1 to 7 (1: do not agree at all; 7: fully agree).

From the subscale interest/enjoyment and perceived choice all available statements were used. Interest/ enjoyment is the only subscale that is an indicator of the subjective experience per se while the other subscales are related to the satisfaction of basic psychological needs that promote intrinsic motivation [14]. The perceived choice is related to the psychological need for autonomy and competence.

The subscale value/usefulness was represented by the statements "I believe composing music could be of some value to me." and "I would be willing to do this again.. The value/usefulness subscale measures in how far people internalize and become self-regulating with respect to activities that they experience as useful or valuable for themselves.

Finally, the subscale man-machine relation was represented by the statements "I felt really distant to the robot.", "I don't feel like I could really trust the robot.", "I'd like a chance to interact with the robot more often.," "I'd really prefer not to interact with the robot in the future.", and "I felt like I could really trust the robot.." Man-machinerelation evaluates the degree of a person's feelings towards and interactions with the device.

\section{Secondary outcomes (recorded)}

During each task performance, the ARMin system recorded the total training time, time of free movement, i.e., duration of final phase, and root-mean-square (RMS) of the end effector velocity profile. RMS of the end effector velocity profile approximates the energy expenditure [43] and was recently used in neuromuscular therapy studies [44].

\section{Secondary outcomes (self-reported)}

After the performance of the first two tasks, the subject was asked to report the most preferred task. The subject was instructed to estimate the perceived training time after each task. This perceived training time was compared later to the actual training time (relative perceived training time). Additionally, the perceived effort was rated: Via ratings along a Borg Scale from one to twenty the subject grades, how exhausting the task is perceived [45]. After each task, the subject was asked whether he or she would like to receive the created music piece as mp3. Their answer was used to assess the perceived product value.

\section{Subject data}

We assessed age and sex of each subject. Furthermore, personality profiles were screened with the Ten Item Personality Inventory (TIPI). In the TIPI test, statement sentences are presented that are related to ten personality traits. Test subjects are instructed to assign to which degree they identify with these traits along a Likert scale ranging from 1 to 7 (1: do not agree at all; 7: fully agree). Creativity was evaluated with the sub-test on verbal creativity out of the Torrance Test of Creative Thinking (TTCT) [46]. This test measures verbal creativity along the two dimensions fluency (number of words) and flexibility (number of different semantic categories of relevant 
responses). A stimulus word (in our case "garden") is presented. The task is to list as many words as possible associated with the stimulus word within 60 seconds. TIPI and TTCT were assessed to get an overall impression of the study population's variability regarding personality and creativity.

\section{Statistical analysis}

We used linear mixed models to analyze each IMI-item (interest/enjoyment, perceived choice, value/usefulness, man-machine relation), the recorded measures (training time, free movement time, RMS of the end effector velocity profile), and the self-reported measures relative perceived training time and perceived size of effort. The only random effect was the individual subject. We determined significant effects of promoting creativity $(C+$ instead of $\mathrm{C}-$ ), the omission of a visual display ( $\mathrm{V}-$ instead of $\mathrm{V}+$ ), and interaction effects. The significant effects were presented as within-subject corrected (i.e., relative to the mean value of the subject over all performed tasks).

For the preferred task, we reported the number of subjects who stated a task as being their preference. For the perceived size of product value, we reported the number of positive and negative answers.

\section{Results}

Sixteen healthy subjects (ten males, six females, mean age: 27.2 years, standard deviation: 4.1 years) with no known motor or cognitive deficit participated in this study. The detailed results are reported in the Appendix Summary of results in Table 5. We visually inspected the residuals of the linear mixed models.

\section{Primary outcomes}

Linear mixed models analysis of the IMI subscales interest/enjoyment and perceived choice showed a significant positive effect of promoting creativity $(\mathrm{C}+$ instead of $\mathrm{C}-$ ) as presented in Table 2 and Fig. 4. No significant effects for man-machine relation and value/usefulness were found.

\section{Secondary outcomes (recorded)}

Linear mixed models of the total training time and RMS of the velocity profile showed a significant interaction effect in promotion of creativity and omission of visual display as presented in Table 3. In the conditions without a visual display, promotion of creativity leads to less total training time and higher RMS of velocity while the opposite effects are found in conditions with a visual display. No significant effects in free movement time were found.

\section{Secondary outcomes (self-reported)}

Fourteen out of sixteen subjects preferred the conditions promoting creativity $(\mathrm{C}+)$ to the conditions not promoting
Table 2 Linear mixed models analysis of the fixed effects promotion of creativity and omission of visual display on the IMI subscales interest/enjoyment, perceived competence, man-machine relation and value/usefulness

\begin{tabular}{|c|c|c|c|c|c|}
\hline & Mean (std. error) & $\mathrm{t}$ & $\mathrm{p}$ & $95 \% \mathrm{Cl}$ & \\
\hline & & & & Lower & Upper \\
\hline Interest/enjoy & & & & & \\
\hline Intercept & $5.6(0.2)$ & 26.5 & 0.000 & 5.1 & 6.0 \\
\hline No creativity & $-1.2(0.4)$ & -3.4 & 0.001 & -1.9 & -0.5 \\
\hline Visual display & $0.1(0.1)$ & 0.4 & 0.666 & -0.3 & -0.4 \\
\hline Interaction & $-1.1(0.6)$ & -1.9 & 0.061 & -1.1 & 0.1 \\
\hline Perceived cho & & & & & \\
\hline Intercept & $4.7(0.3)$ & 14.6 & 0.000 & 4.1 & 5.4 \\
\hline No creativity & $-1.2(0.4)$ & -2.7 & 0.010 & -2.1 & -0.3 \\
\hline Visual display & $0.0(0.4)$ & 0.0 & 0.980 & -0.8 & -0.8 \\
\hline Interaction & $-0.9(0.5)$ & -1.6 & 0.107 & -0.9 & 0.2 \\
\hline Man-machine & & & & & \\
\hline Intercept & $5.3(0.3)$ & 18.6 & 0.000 & 4.7 & 5.8 \\
\hline No creativity & $0.0(0.2)$ & 0.0 & 0.976 & -0.4 & -0.4 \\
\hline Visual display & $0.0(0.2)$ & 0.1 & 0.959 & -0.4 & 0.4 \\
\hline Interaction & $0.0(0.4)$ & -0.1 & 0.943 & 0.0 & 0.8 \\
\hline Value/usefuln & & & & & \\
\hline Intercept & $4.9(0.3)$ & 15.3 & 0.000 & 4.2 & 5.5 \\
\hline No creativity & $-0.8(0.5)$ & -1.7 & 0.101 & -1.8 & 0.2 \\
\hline Visual display & $0.2(0.2)$ & 1.2 & 0.252 & -0.1 & 0.5 \\
\hline Interaction & $-0.9(0.7)$ & -1.2 & 0.228 & -0.9 & 0.6 \\
\hline
\end{tabular}

creativity. Linear mixed models of the relative perceived training time and of the perceived size of effort showed no significant effect in promotion of creativity and omission of visual display as presented in Table 4 . In the $\mathrm{C}+$ conditions, the subjects wanted to receive the created music as a file in eleven of 30 trials. In the $\mathrm{C}$ - conditions, as shown in Fig. 5, the subjects wanted to have the created music as a file in three out of eighteen trials.

\section{Subject data}

The TIPI stated a mean value of 4.31 in extraversion (standard deviation: 0.83), 4.56 in agreeableness (0.85), 4.44 in conscientiousness (0.54), 3.72 in emotional stability (1.02), and 4.09 in openness to experience (0.55). The TCTT stated a mean value of 5.06 in flexibility (standard deviation: 1.00) and 14.94 in fluency (3.64).

\section{Discussion}

We could prove that intrinsic motivation is increased by tasks promoting creativity when performing a robotassisted music task. The tasks promoting creativity were preferred and rated more enjoyable than those without 

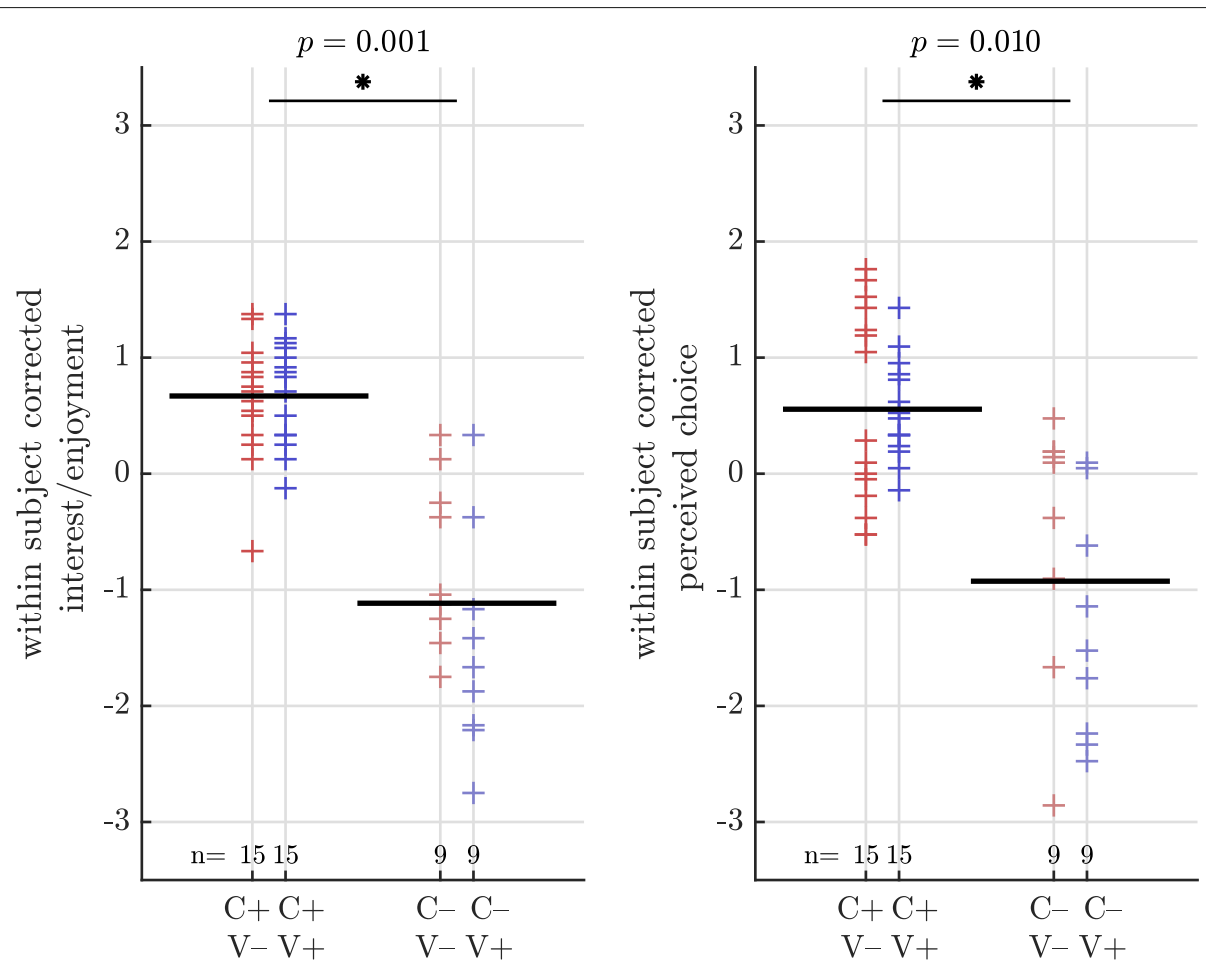

Fig. 4 Within subject corrected rating of subscale interest/enjoyment (left) and perceived competence (right) for visualization of the significant effect in promotion of creativity ( $C+$ instead of $\left.C_{-}\right)$using linear mixed models. The black line indicates the mean of the performances the line is crossing. Each condition was played by a different number of subjects (n)

Table 3 Linear mixed models analysis of the fixed effects promotion of creativity and omission of visual display on total training time, free movement time and RMS of velocity

$$
\text { Mean (std. error) t p } \frac{95 \% \mathrm{Cl}}{\text { Lower Upper }}
$$

Training time $[s]$

\begin{tabular}{|c|c|c|c|c|}
\hline Intercept & $518(29)$ & 17.6 & 0.000458 & 577 \\
\hline No creativity & 236(139) & 1.7 & $0.096-44$ & 516 \\
\hline Visual display & $38(40)$ & 0.9 & $0.348-42$ & 118 \\
\hline Interaction & $-387(149)$ & -2.6 & $0.013-387$ & -87 \\
\hline \multicolumn{5}{|c|}{ Free movement time $[s]$} \\
\hline Intercept & 133(12) & 10.8 & 0.000108 & 157 \\
\hline No creativity & $-37(24)$ & -1.5 & $0.135-86$ & 12 \\
\hline Visual display & $16(17)$ & 0.9 & $0.965-19$ & 51 \\
\hline Interaction & $-20(50)$ & -0.4 & $0.688-20$ & 81 \\
\hline \multicolumn{5}{|c|}{ RMS of the velocity profile } \\
\hline Intercept & $0.09(0.01)$ & 9.20 & 0.0000 .07 & 0.11 \\
\hline No creativity & $-0.02(0.01)$ & -1.70 & $0.092-0.05$ & 0.00 \\
\hline Visual display & $-0.01(0.01)$ & -0.50 & $0.606-0.04$ & 0.02 \\
\hline Interaction & $0.07(0.02)$ & 3.80 & 0.0000 .07 & 0.11 \\
\hline
\end{tabular}

creativity. These results are consistent with previous findings [47] and support the use of music to engage in robot-assisted training. In addition, the game modes that promoted creativity led to increased self-reported autonomy (indicated by IMI subscale of perceived choice).

Table 4 Linear mixed models analysis of the fixed effects promotion of creativity and omission of relative perceived training time and perceived size of effort

\begin{tabular}{llllll}
\hline & Mean (std. error) & $\mathrm{t}$ & $\mathrm{p}$ & \multicolumn{2}{c}{$95 \% \mathrm{Cl}$} \\
\cline { 5 - 6 } & & & Lower & Upper \\
\hline Relative perceived training time [s] & & & & \\
Intercept & 74(50.4) & 1.5 & 0.148 & -27.3 & 175.3 \\
No creativity & $-133.3(100.5)$ & -1.3 & 0.191 & -335.2 & 68.7 \\
Visual display & $-4.9(76.8)$ & -0.1 & 0.949 & -159.3 & 149.4 \\
Interaction & $91.8(149)$ & 0.6 & 0.540 & 91.8 & 391.0 \\
Perceived size of effort [-] & & & & \\
Intercept & $5.1(0.8)$ & 6.8 & 0.000 & 3.6 & 6.6 \\
No creativity & $1.1(1.2)$ & 0.9 & 0.378 & -1.4 & 3.6 \\
Visual display & $0.4(0.7)$ & 0.6 & 0.568 & -1.0 & 1.9 \\
Interaction & $-1.2(2.5)$ & -0.5 & 0.623 & -1.2 & 3.7 \\
\hline
\end{tabular}




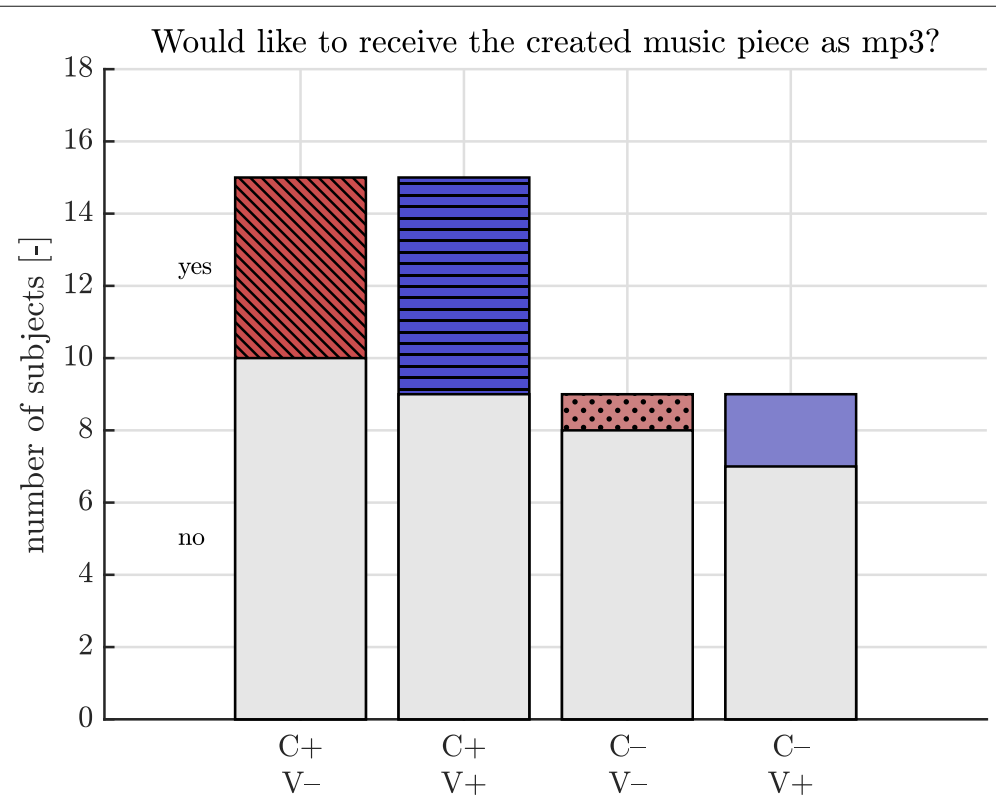

Fig. 5 Perceived size of value indicated by the desire to receive the music on $\mathrm{mp3}$

Promoting creativity had no significant effect on usefulness. However, more subjects wanted to receive the music piece produced in modes where creativity was promoted. Therefore, process (i.e., creation of music piece) and product (i.e., music piece itself) must be discussed separately in game design regarding value.

The omission of a visual display did not affect intrinsic motivation ratings. According to statements of participants, playing without a visual display has been a new and exciting experience for them. However, without a visual display the rules might not be intuitively understood. Non-intuitive game rules may lower the feeling of competence [14]. Although not systematically measured, subjects reported verbally that the conditions without visual display were challenging. Therefore, future studies should measure the IMI subscale perceived competence. Furthermore, the conditions without visual display might benefit from a more detailed audio guide. Accompanying the users throughout the first steps of the game verbally may increase the feeling of competence. For patients in neurorehabilitation therapy it might be even more challenging to understand the task [48]. For these patients, intuitive game design and clear game instructions are especially important. However, playing without a visual display facilitates the use of vision for movement observation which has a positive impact on recovery of motor functions [49]. Furthermore, vision could focus on human-human interaction. Seeing each other is particularly motivating while playing with training devices [50]. In our setup, we expected that the subjects would visually observe the human-robot interaction resulting in a higher man-machine relation. From observation we realized that subjects mainly looked straight ahead to the place where usually a monitor would be expected. As stated by the subjects, they were rather focusing on the auditory display of the game than on the arm movement. Likewise, no difference in man-machine relatedness was found. In further studies without visual displays, patients should be instructed, to visually focus on the arm movements [34, 35].

It is a principal objective of robot-assisted therapy to increase the intensity (i.e., energy expenditure, duration of therapy, number of repetitions) during therapy. In our study, creativity promoting tasks increased energy expenditure without visual display. However, (as shown by significant interaction) energy expenditure decreased with visual display. The possibility to explore the audiohaptic setting seemed to promote more intense moving behavior. On the contrary, when the target position was predefined and visualized $(\mathrm{C}-\mathrm{V}+)$ the subjects moved fast with fewer slow movement phases for decision making. The subjects tried to reach the stated target positions (i.e., "go left", "go right") as fast as possible without resting phases for listening. However, in the condition with visual display where creativity was promoted $(\mathrm{C}+\mathrm{V}+)$ the movements slowed down. In summary, we assume that when there is no visualisation of a reaching task $((\mathrm{V}-)$, i.e., no extrinsically motivators for fast reaching movements), tasks promoting creativity may intrinsically motivate for more intensive movements.

Regardless of the conditions, the subjects voluntarily played on average two additional minutes within 
each eight minutes task. Obviously, the subjects were motivated to voluntarily extend time of arm movement after finishing the guided phases.

Future work could provide haptic guidance or resistance [51]. The decision to use or omit a visual display could be to the user. Alternatively, therapy could start with visual display until proficiency increases and be omitted later, e.g., as an adaptation in task difficulty.

\section{Limitations}

A technical limitation of this study was that subjects just played three of the four conditions. Moreover, the number of participants was restricted to sixteen subjects. All subjects were highly educated, young and healthy subjects. As this game is intended for rehabilitation training of stroke patients the results of this study cannot be directly transferred to a patient population.

Subjects reported that it was difficult to synchronize movements to the beat while playing the game. Movement-beat-synchronization has a potential to support motor training by keeping a stable tempo over a prolonged time [27]. Therefore, the haptics would need to be redesigned to enable an intuitive and easy synchronization of the movement to the beat. Different tempi choices may ease the movement-beat-synchronization.

The audio and haptic cues were designed to provide an equivalent conception of the task when visuals are not present. However, it remains unclear whether the introduction round in the $\mathrm{C}+\mathrm{V}+$ condition was confounding the results of the study.

We conducted the TTCT to receive a quantification of the participants' creativity. The task in this study was specifically creating music. Therefore, the participants' experience in making and creating music would have been of interest.

Another limiting aspect might be the restricted action space for arm movement. A more explorative behavior might have led to longer training times. However, the device is designed for motor training of subjects with moderate to severe arm weakness with a limited workspace. This might have lowered a feeling of movement freedom.

In our prototype game, we implemented music with a very simple rhythmic structure and mostly classical instruments. In the future, several music styles and genres such as rock, pop or classical music could be provided to meet subjective tastes and offer training variety.

\section{Conclusions}

The combination of music and activities promoting creativity in motor training promotes enjoyment, and thus intrinsic motivation of subjects performing robot-assisted training. As the audio-haptic environment is sufficient to create a meaningful gameplay, music tasks can be performed without a visual display.

Promotion of creativity in a gamified task for neurorehabilitation may increase intrinsic motivation in patients but not training intensity in general. At the same time, omission of a visual display may not influence intrinsic motivation or training intensity. However, promotion of creativity differently influences training intensity dependent on the visual display of the task. When promoting creativity, audio-visuo-haptic environments lower training intensity while audio-haptic environments enhance training intensity.

We demonstrated the feasibility of playing an audiohaptic music game and suggest a follow-up study on stroke survivors.

\section{Appendix \\ ARMin}

The skeleton of the robot is designed according to the joints of the human arm, consisting of an upper arm link, lower arm link and a hand module. The upper arm link is connected to the fix robot body by a shoulder joint, and is connected to the other two links by an elbow and wrist joint. These joint-connections enable rotational movement of the exoskeleton links as 3D shoulder rotation, elbow flexion/extension, pro-/supination and wrist flexion/extension. The hand module additionally supports and assesses hand opening and closing. All seven degrees of freedom have two position sensors for redundant measuring of the current angle of the rotated link and actuators to move the links. The interaction between robot and the subject is transferred by cuffs at the upper arm, lower arm and hand module. The interaction forces are assessed by six degrees of freedom torque sensors mounted at the cuffs (Keller 2014). The ARMin robot can be adjusted to the upper arm, lower arm and hand properties. The same robot can be used in right arm and left arm configuration. The shoulder joint position can be set to the individual body size of the subjects. Safety features as mechanical endstops and software endstops for each joint, velocity limitations assure safe applications with healthy and impaired subjects. Using the position sensors and the actuators the ARMin robot features different controllers that support. ARMin is controlled with Simulink Realtime (Mathworks, R2014b).

\section{Summary of results}

The detailed results are reported in Table 5.

\section{Sound examples}

Soundalike 1 and 2 present an audio scene from the listening phase of a creation task: https://drive.google.com/ open?id=0B3qqJ808s5veOVg2UzRCbFJaQVE https://drive. google.com/open?id=0B3qqJ808s5veQmVKS3pUY002Qjg 


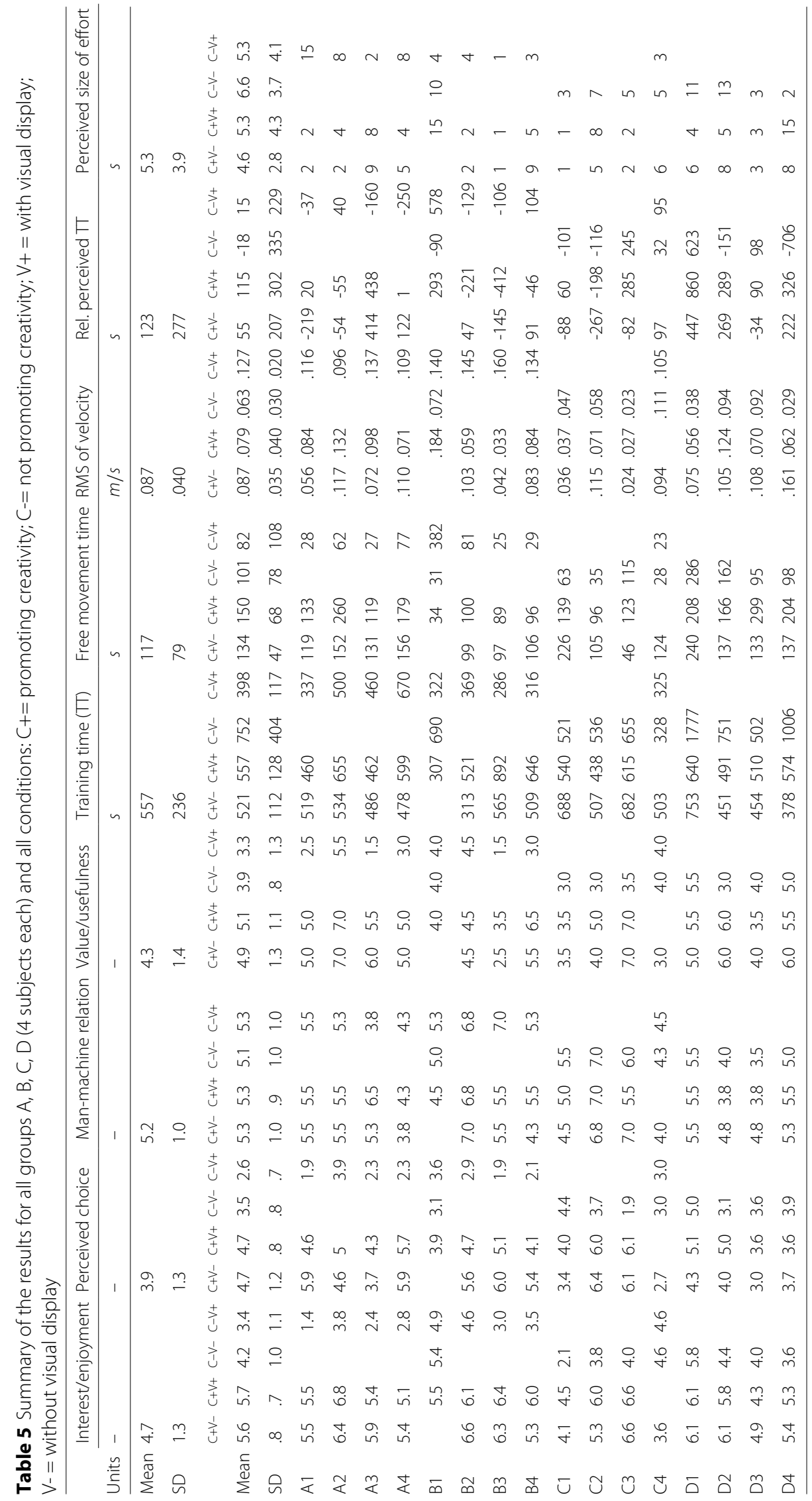




\section{Acknowledgements}

The authors would like to thank Nicolas Gerig and Jaime E. Duarte for their very supportive inputs.

\section{Funding}

This work was supported by the Swiss National Science Foundation (Grant No. SNF-160313) through the National Centre of Competence in Research on Robotics (NCCR) and by the ETH Foundation through ETH Research Grant $\mathrm{ETH}-17$ 13-2.

\section{Authors' contributions}

KB participated in the study design and robot control software development as well as the measurement sessions and data analysis. FS participated in the study design and software development, developed the musical composition, supervised the measurement sessions and data preparation for data analysis. AN participated in the study design and was the main developer of the game. RR supervised the research project. VK participated in the study design and data analysis. All authors read and approved the final manuscript.

\section{Consent for publication}

Written informed consent was obtained from all human subjects for the publication of this report and any accompanying images.

\section{Competing interests}

The authors declare that they have no competing interests.

\section{Publisher's Note}

Springer Nature remains neutral with regard to jurisdictional claims in published maps and institutional affiliations.

\section{Author details}

${ }^{1}$ Sensory-Motor Systems Lab, Department of Health Sciences and Technology, Swiss Federal Institute of Technology (ETH Zurich), Tannenstrasse 1, 8092 Zurich, Switzerland. ${ }^{2}$ Spinal Cord Injury Center, University Hospital Balgrist, University of Zurich, Forchstrasse 340, 8008 Zurich, Switzerland. ${ }^{3}$ Institute for Rehabilitation Science, Humboldt-Universitaet zu Berlin, Berlin, Germany, Unter den Linden 6, 10099 Berlin, Germany. ${ }^{4}$ Institute of Occupational Therapy, School of Health Professions, Zurich University of Applied Sciences, Technikumstrasse 81, 8401 Winterthur, Switzerland.

\section{Received: 19 February 2018 Accepted: 10 July 2018} Published online: 16 August 2018

\section{References}

1. Langhorne P, Coupar F, Pollock A. Motor recovery after stroke: a systematic review. Lancet Neurol. 2009;8(8):741-54. https://doi.org/10. 1016/S1474-4422(09)70150-4.

2. Hesse S, Heß A, Werner C C, Kabbert N, Buschfort R. Effect on arm function and cost of robot-assisted group therapy in subacute patients with stroke and a moderately to severely affected arm: a randomized controlled trial. Clin Rehabil. 2014;28(7):637-47. https://doi.org/10.1177/ 0269215513516967

3. Nordin N, Xie SQ, Wünsche B. Assessment of movement quality in robot- assisted upper limb rehabilitation after stroke: a review. J NeuroEngineering Rehabil. 2014;11:137. https://doi.org/10.1186/17430003-11-137

4. Pollock A, Farmer S, Brady M, Langhorne P, Mead G, Mehrholz J, van Wijck F. Interventions for improving upper limb function after stroke (Review). Cochrane Database Syst Rev. 2014;12(11):0102820. https://doi. org/10.1002/14651858.CD010820.pub2.Copyright.

5. Platz T, Roschka S. Rehabilitative Therapie bei Armlähmungen nach einem Schlaganfall: Patientenversion der Leitlinie der Deutschen Gesellschaft für Neurorehabilitation. Bad Honnef: Hippocampus-Verlag; 2011.

6. Maclean N, Pound P. A critical review of the concept of patient motivation in the literature oh physical rehabilitation,. Soc Sci Med. 2000;50:495-506.

7. Maclean N, Pound P, Wolfe C, Rudd A. Qualitative analysis of stroke patients' motivation for rehabilitation,. BMJ. 2000;321(7268):1051-4. https://doi.org/10.1136/bmj.321.7268.1051.

8. Holmqvist LW, von Koch L. Environmental factors in stroke rehabilitation. BMJ. 2001;322(7301):1501-2. https://doi.org/10.1136/bmj.322.7301.1501.
9. Kwakkel G. Impact of intensity of practice after stroke: Issues for consideration. Disabil Rehabil. 2006;28(13-14):823-30. https://doi.org/10. 1080/09638280500534861.

10. Mehrholz J, Hädrich A, Platz T, Kugler J, Pohl M, Mehrholz J, Hädrich A, Platz T, Kugler J, Pohl M. Electromechanical and robot-assisted arm training for improving generic activities of daily living , arm function, and arm muscle strength after stroke ( Review) Electromechanical and robotassisted arm training for improving generic activities of daily. Stroke. 2012;43(6):. https://doi.org/10.1002/14651858.CD006876.pub3.Copyright.

11. Timmermans AAA, Lemmens RJM, Geers RPJ, Smeets RJEM, Seelen HAM. A comparison of treatment effects after sensor- and robot-based task-oriented arm training in highly functional stroke patients. In: Proceedings of the Annual International Conference of the IEEE Engineering in Medicine and Biology Society, EMBS. New York: IEEE; 2011. p. 3507-3510. https://doi.org/10.1109/IEMBS.2011.6090947.

12. Ryan $R$, Deci E. Self-determination theory and the facilitation of intrinsic motivation, social development, and well-being.. Am Psychol. 2000;55(1): 68-78. https://doi.org/10.1037/0003-066X.55.1.68.0208024.

13. Szalma JL. Individual differences in human-technology interaction: Incorporating variation in human characteristics into human factors and ergonomics research and design. Theor Issues Ergon Sci. 2009;10(5): 381-97. https://doi.org/10.1080/14639220902893613.

14. Ryan R, Deci E. Intrinsic and Extrinsic Motivations: Classic Definitions and New Directions,. Contemp Educ Psychol. 2000;25(1):54-67. https://doi. org/10.1006/ceps.1999.1020.arXiv:1011.1669v3.

15. Lee W, Reeve J, Xue Y, Xiong J. Neural differences between intrinsic reasons for doing versus extrinsic reasons for doing: An fMRI study. Neurosci Res. 2012;73(1):68-72. https://doi.org/10.1016/j.neures.2012.02. 010.NIHMS150003.

16. Putrino D, Zanders H, Hamilton T, Rykman A, Lee P, Edwards DJ. Patient Engagement Is Related to Impairment Reduction During Digital Game-Based Therapy in Stroke. Games Health J. 2017;6(5):295-302. https://doi.org/10.1089/g4h.2016.0108.

17. Nakamura J, Csikszentmihalyi M. The Motivational Sources of Creativity as Viewed from the Paradigm of Positive Psychology. In: The Systems Model of Creativity; 2014. p. 195-206. https://doi.org/10.1007/978-94-0179085-7_12. http://link.springer.com/10.1007/978-94-017-9085-7_12.

18. Prabhu V, Sutton C, Sauser W. Creativity and Certain Personality Traits: Understanding the Mediating Effect of Intrinsic Motivation. Creat Res J. 2008;20(1):53-66. https://doi.org/10.1080/10400410701841955.

19. Eisenberger R, Shanock L. Rewards, Intrinsic Motivation, and Creativity: A Case Study of Conceptual and Methodological Isolation. Creat Res J. 2003:15(2-3):121-30. https://doi.org/10.1080/10400419.2003.9651404.

20. Johnson D, Gardner J, Sweetser P. Motivations for videogame play: Predictors of time spent playing. Comput Hum Behav. 2016;63:805-12. https://doi.org/10.1016/j.chb.2016.06.028.

21. de Jesus SN, Rus CL, Lens W, Imaginário S. Intrinsic Motivation and Creativity Related to Product: A Meta-analysis of the Studies Published Between 1990-2010. Creat Res J. 2013;25(1):80-4. https://doi.org/10. 1080/10400419.2013.752235.

22. Ward TB, Kolomyts Y. Cognition and Creativity. Cambridge: Cambridge University Press; 2012, pp. 93-112.

23. Gebauer L, Vuust P. White Paper: Music interventions in health care Lyngby: Danish Sound Innovation Network; 2014.

24. Friedman N, Chan V, Reinkensmeyer AN, Beroukhim A, Zambrano GJ, Bachman M, Reinkensmeyer DJ. Retraining and assessing hand movement after stroke using the MusicGlove: comparison with conventional hand therapy and isometric grip training. J NeuroEngineering Rehabil. 2014;11(1):76. https://doi.org/10.1186/1743-0003-11-76.

25. Thaut MH, McIntosh GC, Hoemberg V. Neurobiological foundations of neurologic music therapy: Rhythmic entrainment and the motor system. Front Psychol. 2015;6(FEB):1-6. https://doi.org/10.3389/fpsyg.2015.01185.

26. Amengual JL, Rojo N, Veciana de las Heras M, Marco-Pallarés J, Grau-Sánchez J, Schneider S, Vaquero L, Juncadella M, Montero J, Mohammadi B, Rubio F, Rueda N, Duarte E, Grau C, Altenmüller E, Münte TF, Rodríguez-Fornells A. Sensorimotor Plasticity after Music-Supported Therapy in Chronic Stroke Patients Revealed by Transcranial Magnetic Stimulation. PLoS ONE. 2013;8(4):1-10. https://doi.org/10.1371/journal.pone.0061883.

27. Bradt J, Magee WL, Dileo C, Wheeler BL, McGilloway E. Music therapy for acquired brain injury. Cochrane Database Syst Rev. 2010;7:006787. https://doi.org/10.1002/14651858.CD006787.pub2. 
28. Raglio A. Effects of music and music therapy on mood in neurological patients. World J Psychiatry. 2015;5(1):68. https://doi.org/10.5498/wjp.v5. i1.68.

29. Särkämö T, Soto D. Music listening after stroke: Beneficial effects and potential neural mechanisms. Ann N Y Acad Sci. 2012;1252(1):266-81. https://doi.org/10.1111/j.1749-6632.2011.06405.x.

30. Altenmüller E, Schlaug G. Apollo's gift: New aspects of neurologic music therapy. Prog Brain Res. 2015;217:237-52. https://doi.org/10.1016/bs.pbr. 2014.11.029.15334406.

31. Koeneman EJ, Schultz RS, Wolf SL, Herring DE, Koeneman JB. A pneumatic muscle hand therapy device. In: Engineering in Medicine and Biology Society, 2004. IEMBS'04. 26th Annual International Conference of the IEEE, vol 4. New York: IEEE; 2004. p. 2711-2713. https://doi.org/10. 1109/IEMBS.2004.1403777.

32. Schneider S, Schönle PW, Altenmüller E, Münte TF. Using musical instruments to improve motor skill recovery following a stroke. J Neurol. 2007;254(10):1339-46. https://doi.org/10.1007/s00415-006-0523-2.

33. Hermann T. Taxonomy and Definitions for Sonification and Auditory Display. In: Proceedings of the 14th International Conference on Auditory Display. Bielefeld: Center of Excellence - Cognitive Interaction Technology CITEC; 2008. p. 1-8.

34. Koh CL, Pan SL, Jeng JS, Chen BB, Wang YH, Hsueh IP, Hsieh CL. Predicting recovery of voluntary upper extremity movement in subacute stroke patients with severe upper extremity paresis. PLoS ONE. 2015;10(5): 1-15. https://doi.org/10.1371/journal.pone.0126857.

35. Zimmermann-Schlatter A, Schuster C, Puhan MA, Siekierka E, Steurer J. Efficacy of motor imagery in post-stroke rehabilitation: a systematic review. J NeuroEngineering Rehabil. 2008;5(1):8. https://doi.org/10.1186/ 1743-0003-5-8.

36. Moreno R, Mayer R. Interactive Multimodal Learning Environments. Educ Psychol Rev. 2007;19(3):309-26. https://doi.org/10.1007/s10648-0079047-2.0507464v2.

37. Nef T, Mihelj M, Riener R. ARMin: a robot for patient-cooperative arm therapy,. Med Biol Eng Comput. 2007;45(9):887-900. https://doi.org/10. 1007/s11517-007-0226-6.

38. Guidali M, Duschau-Wicke A, Broggi S, Klamroth-Marganska V, NefT, Riener R. A robotic system to train activities of daily living in a virtual environment. Med Biol Eng Comput. 2011;49(10):1213-23. https://doi. org/10.1007/s11517-011-0809-0.

39. Sanchez R, Reinkensmeyer D, Shah P, Liu J, Rao S, Smith R, Cramer S, Rahman T, Bobrow J. Monitoring functional arm movement for home-based therapy after stroke. In: The 26th Annual International Conference of the IEEE Engineering in Medicine and Biology Society, vol 4. New York: IEEE; 2004. p. 4787-4790. https://doi.org/10.1109/IEMBS. 2004.1404325.

40. Unity. Unity - Game Engine. Computer Software. 2017. https://unity3d. com/.

41. Isaac S. Handbook in Research and Evaluation : a Collection of Principles, Methods, and Strategies Useful in the Planning, Design, and Evaluation of Studies in Education and the Behavioral Sciences. San Diego: EdITS; 1995.

42. McAuley E, Duncan T, Tammen W. Psychometric properties of the Intrinsic Motivation Inventory in a competitive sport setting: a confirmatory factor analysis. Research quarterly for exercise and sport 1989;60(1):48-58. https://doi.org/10.1080/02701367.1989.10607413. http://www.tandfonline.com/doi/abs/10.1080/02701367.1989.10607413.

43. Van Der Pas SC, Verbunt JA, Breukelaar DE, Van Woerden R, Seelen HA. Assessment of arm activity using triaxial accelerometry in patients with a stroke. Arch Phys Med Rehabil. 2011;92(9):1437-42. https://doi.org/10. 1016/j.apmr.2011.02.021.

44. Goršič M, Cikajlo I, Goljar N, Novak D. A multisession evaluation of an adaptive competitive arm rehabilitation game. J NeuroEngineering Rehab. 2017;14(1):128. https://doi.org/10.1186/s12984-017-0336-9.

45. Borg G. Borg's perceived exertion and pain scales. Hum Kinet. 1998;August:104. https://doi.org/10.1097/00005768-199809000-00018.

46. Torrance EP. Empirical validation of criterion-referenced indicators of creative ability through a longitudinal study. Creat Child Adult Q. $1981 ; 6(3): 136-140$.

47. Friedman N, Chan V, Zondervan D, Bachman M, Reinkensmeyer DJ. MusicGlove: motivating and quantifying hand. In: 33rd Annual
International Conference of the IEEE MBS. New York: IEEE; 2011. p. 2359-2363.

48. Hénon H, Durieu I, Guerouaou D, Lebert F, Pasquier F, Leys D. Poststroke dementia: incidence and relationship to prestroke cognitive decline. Neurology. 2001;57(7):1216-22. https://doi.org/10.1212/WNL.57.7.1216.

49. Ertelt D, Small S, Solodkin A, Dettmers C, McNamara A, Binkofski F, Buccino G. Action observation has a positive impact on rehabilitation of motor deficits after stroke. Neurolmage. 2007;36(SUPPL. 2):164-73. https://doi.org/10.1016/j.neuroimage.2007.03.043.

50. Johnson MJ, Loureiro RCV, Harwin WS. Collaborative tele-rehabilitation and robot-mediated therapy for stroke rehabilitation at home or clinic. Intel Serv Robotics. 2008;1(2):109-21. https://doi.org/10.1007/s11370007-0010-3.

51. Baur K, Wolf $P$, Riener $R$, Duarte J. Making neurorehabilitation fun: Multiplayer training via damping forces balancing differences in skill levels. In: Proceedings of the 2017 IEEE International Conference on Rehabilitation Robotics, ICORR 2017. New York: IEEE; 2017. https://doi.org/10.1109/ICORR.2017.8009359.
Ready to submit your research? Choose BMC and benefit from:

- fast, convenient online submission

- thorough peer review by experienced researchers in your field

- rapid publication on acceptance

- support for research data, including large and complex data types

- gold Open Access which fosters wider collaboration and increased citations

- maximum visibility for your research: over $100 \mathrm{M}$ website views per year

At BMC, research is always in progress.

Learn more biomedcentral.com/submissions 